\title{
Thymoquinone with Metformin Decreases Fasting, Post Prandial Glucose, and HbA1c in Type 2 Diabetic Patients
}

\author{
Authors \\ Shoukath M. Ali', Paul Chen'1, Saifuddin Sheikh', Ateeq Ahmad', Moghis Ahmad', Mahesh Paithankar², Brijesh Desai², \\ Piyush Patel ${ }^{2}$, Mujtaba Khan ${ }^{2}$, Alok Chaturvedi ${ }^{2}$, Ronak Patel ${ }^{3}$, Dharmendra T. Panchal ${ }^{4}$, Kuntal Shah ${ }^{5}$, Vipul Chavda ${ }^{6}$, \\ Banshi D. Saboo ${ }^{7}$, Alpesh Patel ${ }^{8}$, Imran Ahmad ${ }^{1}$
}

\section{Affiliations}

1 Jina Pharmaceuticals Inc., Libertyville, IL, USA

2 Intas Pharmaceuticals Limited, Ahmedabad, Gujarat, India

3 Lambda Therapeutics Research Limited, Ahmedabad, Gujarat, India

4 Samvedna Hospital Multispecialty, Ahmedabad, Gujarat, India

5 Bodyline Hospitals, Ahmedabad, Gujarat, India

6 Rudraksha Hospital, Bareja, Gujarat, India

7 Bakeri Medical Research Center, Ahmedabad, Gujarat, India

8 Shree Nidhi Heart \& Medial Hospital, Mehsana, Gujarat, India

Key words

Nigella sativa, thymoquinone, diabetes mellitus, antihyperglycemic

received 08.12 .2020

accepted 31.01.2021

published online $\quad 08.03 .2021$

\author{
Bibliography \\ Drug Res 2021; 71: 302-306 \\ DOI 10.1055/a-1388-5415 \\ ISSN 2194-9379
}

(c) 2021. Thieme. All rights reserved.

Georg Thieme Verlag KG, Rüdigerstraße 14,

70469 Stuttgart · Germany

Correspondence

Imran Ahmad, Ph.D.

Jina Pharmaceuticals, Inc.

28100 N. Ashley Circle

Suite 103

Libertyville

60048 IL

USA

Tel.: + 1(847) 573-0771

Imran@jinapharma.com

\section{ABSTRACT}

Objective Antihyperglycemic activity of Thymoquinone (TQ) was evaluated in diabetic mouse model and patients.

Methods TQ $(50 \mathrm{mg} / \mathrm{kg})$ was orally administered daily for 21 days in combination with metformin in diabetic mice and a reduction on blood glucose level was monitored. In human, a 90-day randomized study was carried out in 60 Type 2 Diabetes mellitus patients to evaluate safety and efficacy of TQ administration with metformin in a 3-arm study. Patients in arm 1 (T1) received 1 tablet of metformin SR $1000 \mathrm{mg}$ and 1 tablet of TQ $50 \mathrm{mg}$ once daily. The second arm (T2) patients received 1 tablet of metformin SR $1000 \mathrm{mg}$ and 2 tablets of TQ $50 \mathrm{mg}$ once daily. Patients in arm $3(R)$ received 1 tablet of metformin SR $1000 \mathrm{mg}$ only.

Results The diabetic mice treated with combination of TQ and metformin showed significant decrease in blood sugar compared to those treated with only metformin. In patients who completed the study, the glycated hemoglobin ( $\mathrm{HbA} 1 \mathrm{c})$ values in $\mathrm{T} 1, \mathrm{~T} 2$ and $\mathrm{R}$ decreased after 3 months from 7.2, 7.2 and 7.3 to $6.7,6.8$, and 7.1, respectively. A greater reduction in Fasting Blood Glucose and Post Prandial Blood Glucose was also observed in $\mathrm{T} 1$ and $\mathrm{T} 2$ arms compared to $\mathrm{R}$.

Conclusion At dose levels of 50 and $100 \mathrm{mg}$ of TQ combined with a daily dose of $1000 \mathrm{mg}$ Metformin demonstrated a reduction in the levels of $\mathrm{HbA} 1 \mathrm{c}$ and blood glucose compared to the standard treatment of diabetic patients with metformin alone. 


\section{Introduction}

Type 2 Diabetes mellitus (Type $2 \mathrm{DM}$ ) is the most common chronic metabolic disorder characterized by hyperglycemia [1]. Type 2 DM is associated with major systemic complications, resulting in disabilities, and therefore it is considered a serious comorbidity factor $[2,3]$. Metformin is the most widely prescribed oral drug which has shown to lower the blood glucose among Type 2 DM patients largely by decreasing hepatic glucose output [4]. Despite its ability to lower blood glucose levels, a significant proportion of patients do not achieve optimum glucose homeostasis with monotherapy [5, 6] and require a combination therapy with additional therapeutic agents to achieve adequate glycemic control $[7,8]$. Metformin in combination with Sulfonylurea, DPP-4-inhibitor, Thiazolidinedione, SGLT-2 inhibitor along with some other class of anti-diabetic drugs have been used for the treatment of Type 2 DM patients $[9,10]$. However, these combination therapies may increase the risk of hypoglycemia [11] and cardiovascular events [12-14]. Hence, there is a need for a safe and more effective agent for a better control of hyperglycemia as an add-on therapy to metformin to treat Type 2 DM patients.

Several researchers have investigated the effect of medicinal herbs and found to be a beneficial adjuvant agent to oral antidiabetic drugs because of their integrated effects. Among medicinal herbs, Nigella sativa was shown to significantly improve hyperglycemia and diabetes control after treatment with a much decrease in blood glucose [15-17]. Thymoquinone (TQ) is a phytochemical abundantly present in the seeds of Nigella sativa, which is often referred to as black cumin seeds or black caraway seeds. Biological activities of Nigella sativa seeds including hepatoprotection, suppression of oxidative stress, and inflammation are mainly ascribed to its essential constituent, TQ [18-21]. The ability of Nigella sativa seeds to reduce hyperglycemia and insulin resistance in diabetic patients have also been reported [22]. In a preclinical study in Streptozotocin (STZ)-induced diabetic rats, treatment with a combination of Nigella sativa oil and metformin resulted in a better glycemic control when compare to the use of either Nigella sativa oil or metformin alone [23]. However, not many clinical studies have been conducted with pure TQ presumably due to its poor solubility in water, instability at room temperature, sublimation, degradation when exposed to light, and instability in aqueous solution at extreme $\mathrm{pH}$. To minimize the instability of TQ and to improve its bioavailability when ingested orally, we have developed a novel, well-characterized, stable, lipid-based, enteric coated TQ tablet and evaluated its therapeutic efficacy in combination with metformin in STZ-induced diabetic mice. The significant reduction $(p=0.02)$ in blood glucose level in TQ and metformin treated mice vs. metformin treatment alone prompted us to further investigate the TQ tablet safety and therapeutic efficacy in Type $2 \mathrm{DM}$ patients.

\section{Methods}

\section{Preparation of TQ Tablets}

Enteric coated TQ tablets $(50 \mathrm{mg}$ ) were manufactured by granulating TQ with inactive ingredients and lipids followed by blending. The resulted mixture was then compressed using D Tooling machine. The blended tablets were seal coated followed by enteric coa- ting in an auto coater and dried. The tablets were subjected to physical and chemical characterization including TQ, lipid content, microbial assay, and in vitro dissolution properties.

\section{Pre-clinical}

Male ICR (CD1) mice (Envigo, IN, USA) at 8-9 weeks of age were used. Mice (5/cage) were housed in polycarbonate cages and accordance with the inhouse standard operating procedures and "Guide for the Care and Use of Laboratory Animals" by the National Institutes of Health.

A total of 30 mice were administered i.p. with fresh $150 \mathrm{mg} / \mathrm{kg}$ STZ solution [24] prepared in $1.0 \mathrm{mM}$ citrate buffer $(\mathrm{pH} 4.5)$ at $10 \mathrm{~mL} / \mathrm{kg}$. After 3 weeks, fasting $(6 \pm 0.5 \mathrm{~h})$ blood glucose level (BGL) of each mice was measured after drawing blood from tail vein with OneTouch Ultra Glucometer and OneTouch Ultra Test Strips Blue (LifeScan Inc., NJ, USA). Blood samples with "HI" (>600 mg/ $\mathrm{dL}$ ) reading on glucometer were diluted with normal saline and retested to calculate blood glucose level (BGL) values. The dilution linearity of the blood samples was reliable and the correlation coefficient $\left(R^{2}\right)$ of the dilution linearity was found to be $0.997-0.999$ in normal mice and STZ-induced diabetic mice. Twenty mice with BGL of $250 \mathrm{mg} / \mathrm{dL}$ or higher were considered diabetic and used in this study. Diabetic mice were randomized into $A$ and $B$ groups (10 mice/group) based on the BGL. The group average values of $B G L$ were comparable (A: $443 \pm 102$ vs. $B: 445 \pm 94 \mathrm{mg} / \mathrm{dL}$ ) before the treatment. Group A received an oral administration of metformin at a dose of $200 \mathrm{mg} / \mathrm{kg}$ every day for 21 days. Group B received an oral administration of metformin + TQ $(200 \mathrm{mg} / \mathrm{kg}+50 \mathrm{mg} / \mathrm{kg})$ every day for 21 days [25].

\section{Clinical Study - Safety and Efficacy in Type 2 DM Patients}

A randomized, open label, prospective, three-arm, parallel, multicenter study was carried out to evaluate safety and efficacy of TQ administration with metformin in Type $2 \mathrm{DM}$ patients. Male and female patients with Type $2 \mathrm{DM}$ having the $\mathrm{HbA} 1 \mathrm{c} \geq 7 \%$ and $\leq 7.5 \%$, aged between 18 and 65 having body mass index between $18 \mathrm{~kg} /$ $\mathrm{m}^{2}$ and $30 \mathrm{~kg} / \mathrm{m}^{2}$, and receiving stable dose of metformin $(1000 \mathrm{mg} /$ day) for the last 3 months were enrolled in the study. The study was conducted in compliance with the protocol and in adherence to good clinical practices as per declaration of Helsinki (Fortaleza, 2013); ICMR Ethical Guidelines of Biomedical Research on Human Patients, ICH E6 (R2) “Guidelines on Good Clinical Practice 2016, and as per the Guidelines for Clinical Trials on Pharmaceutical Products in India issued by the Central Drugs Standard Control Organization, Ministry of Health, Government of India. The protocol, subject information sheet and subject consent forms were approved by Ethics Committee at each site.

A total of 60 Type 2 DM patients (32 males, 28 females) aged 27-64 years were randomized using SAS statistical software version 9.4 (SAS Institute Inc., USA) according to inclusion and exclusion criteria into 3 arms, Test arm 1 (T1), Test arm 2 (T2), and Reference arm $3(R)$. Patients in arm 1 received 1 tablet of metformin SR $1000 \mathrm{mg}$ once daily and 1 tablet of TQ $50 \mathrm{mg}$. Patients in arm 2 received 1 tablet of metformin SR $1000 \mathrm{mg}$ and 2 tablets of TQ $50 \mathrm{mg}$. Patients in arm 3 received only 1 tablet of metformin SR $1000 \mathrm{mg}$. All patients received treatment for 90 days. 
The safety was assessed by evaluating changes from baseline to significantly higher in the assessment of adverse event (AE) reporting, clinical laboratory tests, physical examinations, electrocardiogram, and vital signs. Adverse events were assessed for severity and their relationship to the drugs. All 60 patients who were randomized and received at least one dose of study medication were considered for safety analysis. SAS Version 9.4 (SAS Institute Inc., USA) was used for statistical and safety analysis of TQ and metformin.

Patients achieving glycated hemoglobin ( $\mathrm{HbA} 1 \mathrm{c})<7 \%$ at 90 days were compared with baseline. A point estimate and $95 \%$ confidence interval were computed for primary efficacy endpoint $\mathrm{HbA} 1 \mathrm{c}$ of the treatment arms and their differences ( $\mathrm{T} 1$ and $\mathrm{T} 2 \mathrm{vs}$. $\mathrm{R}$ ). The change in fasting blood glucose (FBG) and change on post prandial (after food intake) blood glucose (PPBG) were also compared at 90 days. Out of 60 patients, 45 patients completed the study (T1 $(n=13), T 2(n=18)$ and $R(n=14)$ with no major protocol deviation. The remaining 15 patients withdrew their consent to participate further in the trial.

\section{Results}

A stable well-characterized enteric coated tablet of TQ was developed and characterized by physical and chemical studies. The stability studies demonstrated that TQ and lipids were stable at $25{ }^{\circ} \mathrm{C}$

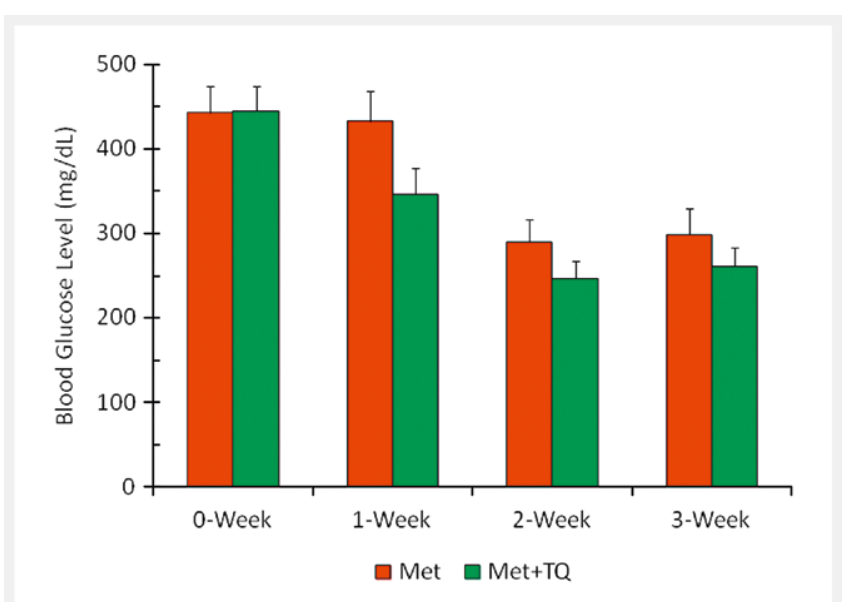

- Fig. 1 Blood glucose levels in Thymoquinone (TQ) + Metformin (Met) vs. Met treated mice. Data represent mean $\pm \operatorname{SE}(n=10)$; Two-factor ANOVA was performed for statistical analysis of animal data and p-value was less than 0.5 when comparing TQ/Met vs Met over 3-week period. up to 18 months. The in vitro dissolution studies in acidic media $(0.1 \mathrm{~N} \mathrm{HCl})$ showed no release of TQ whereas, it was released in phosphate buffer $(\mathrm{pH} 6.8)$ indicating TQ release in the intestine.

The anti-diabetic (hypoglycemic) effect of TQ in combination with metformin (Met) was evaluated in streptozotocin (STZ) - induced diabetes mellitus in male ICR (CD-1) mice. Mice treated with either Met at $200 \mathrm{mg} / \mathrm{kg}$, or TQ/Met at $50 / 200 \mathrm{mg} / \mathrm{kg}$ every day for 3 weeks resulted in $299 \pm 96 \mathrm{mg} / \mathrm{dL}$ BGL, a $32.5 \%$ reduction, while the TQ/Met group was $261 \pm 70 \mathrm{mg} / \mathrm{dL}$, a $41.3 \%$ reduction in BGL. A significant reduction ( $p=0.02)$ in $B G L$ in TQ/Met treated mice vs. Met treated mice was observed ( $\triangleright$ Fig. 1).

In clinical study, a daily dose of TQ (50 mg or $100 \mathrm{mg}$ ) in combination with metformin SR (1000 mg) tablet was evaluated. The demographic and other baseline characteristics of Type 2 DM patients are described in the Table 1.

The safety of the patients was assessed based on the number of adverse events (AEs) observed till end of the study. A total of $13 \mathrm{AEs}$ were reported by 11 (18.3\%) of the 60 patients who were dosed in the trial. In treatment arm T1, 3 (15\%) patients reported $4 \mathrm{AEs}$, while 7 AEs were reported by 6 (28.6\%) patients in arm T2 whereas. 2 (10.5\%) patients in the arm $\mathrm{R}$ reported $2 \mathrm{AEs}$. The adverse events were diarrhea, epigastric pain, abdominal pain and stomachache. The outcome of the adverse event was "resolved" for all 13 AEs. None of the patients treated experienced serious adverse events.

Patients who completed the study, the values of HbA1c at 90 days in $\mathrm{T} 1, \mathrm{~T} 2$ and $\mathrm{R}$ were reduced to $6.7,6.8$, and 7.1 from 7.2, 7.2 and 7.3 respectively ( $\triangleright$ Table 2 ). A significant number of patients showed decreased $\mathrm{HbA} 1 \mathrm{c}<7 \%$ as following. T1-69.2\% patients, T2-61.1\% patients and $21.4 \%$ patients in $\mathrm{R}$ at 90 days ( $\mathbf{F i g . ~} \mathbf{2}$ ). The change in FBG and PPBG were also evaluated at 90 days. The decrease in mean FBG was $29.7 \mathrm{mg} / \mathrm{dL}, 14.9 \mathrm{mg} / \mathrm{dL}$ and $18.3 \mathrm{mg} /$ $\mathrm{dL}$ in $\mathrm{T} 1, \mathrm{~T} 2$ and $\mathrm{R}$ respectively whereas, the decrease in mean PPBG was $51.9 \mathrm{mg} / \mathrm{dL}, 41.7 \mathrm{mg} / \mathrm{dL}$ and $29.5 \mathrm{mg} / \mathrm{dL}$ in $\mathrm{T} 1$, T2 and $\mathrm{R}$ respectively ( $\triangleright$ Table 3 ). As compared to $R$, higher reduction in PPBG was observed in $\mathrm{T} 1$ and $\mathrm{T} 2$ arms.

\section{Discussion}

Previous studies demonstrated the anti-hyperglycemic effects of Nigella sativa in Type 2 DM patients where reduction in the levels of fasting blood glucose (FBG), postprandial blood glucose (PPBG), $\mathrm{HbA} 1 \mathrm{c}$, and insulin resistance were observed $[22,26]$. The clinical evaluation of oral TQ has not been reported presumably due to its poor solubility and instability. To improve its bioavailability and

Table 1 Demographic and other baseline characteristics of the patients.

\begin{tabular}{|l|l|l|l|}
\hline Parameter (Units) & T1 Mean \pm SE & T2 Mean \pm SE & R Mean \pm SE \\
\hline Age (years) & $50 \pm 3.1$ & $48 \pm 2.5$ & $49 \pm 1.7$ \\
\hline Height $(\mathrm{cm})$ & $162 \pm 3.3$ & $160 \pm 2.2$ & $163 \pm 2.1$ \\
\hline Weight $(\mathrm{kg})$ & $63.3 \pm 3.1$ & $65.8 \pm 2.3$ & $67.0 \pm 2.4$ \\
\hline BMl $\left(\mathrm{kg} / \mathrm{m}^{2}\right)$ & $24.1 \pm 0.9$ & $25.6 \pm 0.8$ & $25.3 \pm 0.8$ \\
\hline Gender & & & $65 \pm 1.4$ \\
\hline Male & $9(69.2 \%)$ & $8(44.4 \%)$ & $9(64.3 \%)$ \\
\hline Female & $4(30.8 \%)$ & $10(55.6 \%)$ & $5(35.7 \%)$ \\
\hline
\end{tabular}

T1 $(\mathrm{N}=13)=$ Metformin SR tablet $(1000 \mathrm{mg})$ and Thymoquinone tablet $(50 \mathrm{mg}) . \mathrm{T} 2(\mathrm{~N}=18)=$ Metformin SR tablet $(1000 \mathrm{mg})$ and Thymoquinone tablet (50 mg; 2 tablets). $R(N=14)=$ Metformin tablet SR (1000 mg). Data for age, height, weight, and BMI represent Mean \pm SE. 
- Table 2 Decrease of HbA1c levels in patients treated with Metformin with or without Thymoquinone.

\begin{tabular}{|l|c|c|c|}
\hline \multicolumn{5}{|c|}{ T1 Mean \pm SE } & T2 Mean \pm SE & R Mean \pm SE \\
\hline Day 1 & $55.0(0.4)$ & $55.0(0.4)$ & $56.0(0.4)$ \\
\hline Day 90 & $50.0(0.6)$ & $51.0(0.7)$ & $54.0(0.6)$ \\
\hline \multicolumn{4}{|c|}{ HbA1c (\%) } \\
\hline Day 1 & $7.2(0.1)$ & $7.2(0.1)$ & $7.3(0.1)$ \\
\hline Day 90 & $6.7(0.1)$ & $6.8(0.1)$ & $7.1(0.1)$ \\
\hline
\end{tabular}

T1 $(\mathrm{N}=13)=$ Metformin SR tablet $(1000 \mathrm{mg})$ and Thymoquinone tablet $(50 \mathrm{mg})$. T2 $(\mathrm{N}=18)=$ Metformin SR tablet $(1000 \mathrm{mg})$ and Thymoquinone tablet (50 mg; 2 tablets). $R(N=14)=$ Metformin tablet SR (1000 mg).

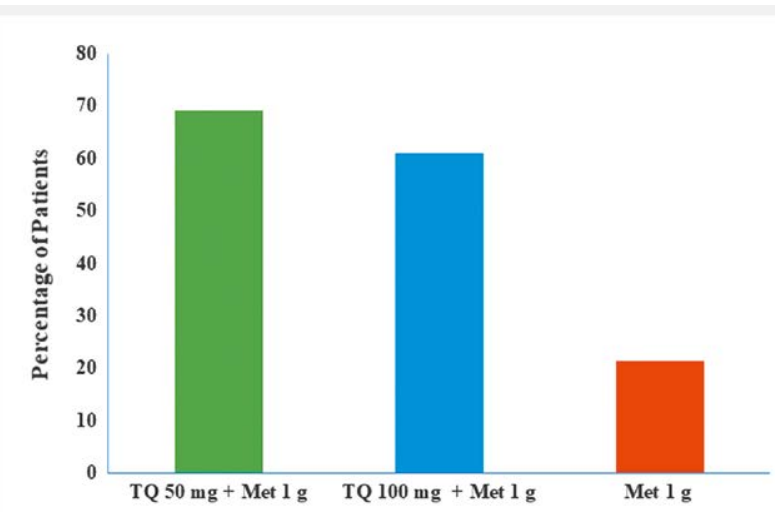

- Fig. 2 Percentage of patients achieving $\mathrm{HbA} 1 \mathrm{c}<7$ at 90 days. $\mathrm{TQ}=$ Thymoquinone; Met= Metformin; $\mathrm{g}=$ gram .

- Table 3 Change in Fasting Blood Glucose (FBG) and Post Prandial Blood Glucose (PPBG) levels in Patients.

\begin{tabular}{|c|c|c|c|}
\hline & $\mathrm{T} 1$ Mean $\pm \mathrm{SE}$ & $\mathrm{T} 2$ Mean $\pm \mathrm{SE}$ & $\mathrm{R}$ Mean $\pm \mathrm{SE}$ \\
\hline \multicolumn{4}{|l|}{ FBG } \\
\hline Day 1 & $144.0 \pm 21.6$ & $118.0 \pm 5.6$ & $129.7 \pm 6.9$ \\
\hline Day 90 & $114.3 \pm 8.6$ & $103.2 \pm 4.4$ & $111.4 \pm 6.3$ \\
\hline \multicolumn{4}{|l|}{ PPBG } \\
\hline Day 1 & $199.8 \pm 28.5$ & $180.3 \pm 12.4$ & $191.1 \pm 10.8$ \\
\hline Day 90 & $147.9 \pm 10.7$ & $138.6 \pm 6.6$ & $161.7 \pm 7.7$ \\
\hline \multicolumn{4}{|c|}{$\begin{array}{l}\text { T1 }(\mathrm{N}=13)=\text { Metformin SR tablet }(1000 \mathrm{mg}) \text { and Thymoquinone } \\
\text { tablet }(50 \mathrm{mg}) . \mathrm{T} 2(\mathrm{~N}=18)=\text { Metformin SR tablet }(1000 \mathrm{mg}) \text { and } \\
\text { Thymoquinone tablet }(50 \mathrm{mg} ; 2 \text { tablets }) . \mathrm{R}(\mathrm{N}=14)=\text { Metformin } \\
\text { tablet SR }(1000 \mathrm{mg}) .\end{array}$} \\
\hline
\end{tabular}

eschew the instability, TQ tablets were formulated with lipids and were enteric coated.

The primary efficacy endpoint results demonstrated that $\mathrm{HbA} 1 \mathrm{c}$ values were reduced more significantly once TQ was added to the metformin regimen compared to metformin SR monotherapy. These results are consistent with the findings reported ${ }^{12}$ where reduction in $\mathrm{HbA} 1 \mathrm{c}$ was observed after 12 weeks of treatment with $2 \mathrm{gm} /$ day Nigella sativa adjuvant therapy along with anti-diabetic medications in Type 2 DM patients. Similar observations were also reported [27] using $5 \mathrm{gm} /$ day Nigella sativa tea for 6 months and with $2 \mathrm{gm} /$ day of
Nigella sativa for 1 year [28]; in addition to standard medication (metformin, sulfonylureas) in Type 2 DM patients. In the present study, a higher reduction in $\mathrm{HbA} 1 \mathrm{c}$ in $\mathrm{T} 1$ and $\mathrm{T} 2$ in 90 days compared to $\mathrm{R}$ could be attributed to TQ add-on to metformin SR.

A significantly more patients showed pronounced effect where $\mathrm{HbA} 1 \mathrm{c}<7 \%$ was observed after combination treatment with TQ and metformin. The proportion of patients with $\mathrm{HbA} 1 \mathrm{c}<7 \%$ at the EOS were almost 3 times with TQ and metformin compared to metformin alone. It has been reported that combination of metformin and sulfonylurea treatment showed only $9 \%$ patients attained HbA 1 c $<7 \%$ after 24 weeks [29]. In other findings $53.1 \%$ Type 2 DM patients achieved $\mathrm{HbA} 1 \mathrm{c}<7 \%$ at 3 months with sitagliptin $(50 \mathrm{mg} /$ day) add-on to the pre-existing anti-diabetic therapy [30]. Further, TQ and metformin combination treatment in this study resulted in early significant therapeutic outcome (90 days). In contrast, therapeutic outcome takes longer ( 24 weeks) with other combinations such as treatment with dapagliflozin $(10 \mathrm{mg})+$ metformin $(1500-$ $2000 \mathrm{mg}$ ) showed only $22.2 \%$ patients who achieved $\mathrm{HbA} 1 \mathrm{c}<7.0$ vs. $18.3 \%$ patients treated with saxagliptin $(5 \mathrm{mg})+$ metformin (1500-2000 mg) [31]. The mechanism how TQ lowering glycemic effect is not known however, previous studies using Nigella sativa have shown that secretion of insulin increases by inducing $\beta$-cell proliferation and regeneration [32,33]. Other investigators have reported that Nigella sativa induces hypoglycemic effect via tissue sensitization to insulin and system glucose homeostasis in diabetic patients [34, 35]. It is also reported that hypoglycemic effect of Nigella sativa is due to the peripheral insulin resistance and $\beta$-cell function [36]. TQ being major component of Nigella sativa may induce hypoglycemic effect in a similar mechanistic pathway as described for Nigella sativa.

As TQ is naturally occurring molecule it was found to show no serious adverse effects in patients treated for 3 months. In addition, no patient encountered hypoglycemia during the clinical trial which indicated that the TQ add-on therapy with metformin is safe and well-tolerated in patients with Type $2 \mathrm{DM}$. Since a well-controlled blood glucose and lower serum levels of inflammatory markers [37, 38] are important to minimize systemic long-term Type 2 DM-associated damages, addition of TQ to the existing treatment regimen may have beneficial effects.

\section{Conclusion}

Preclinical and clinical study demonstrates that TQ has distinct antihyperglycemic effects when added to metformin therapy. In addition, this combination therapy was safe and resulted in better control of diabetes compared to metformin alone. It is concluded that TQ may be safely used as an adjunct therapy to conventional drugs to achieve better glycemic control in Type 2 diabetes patients.

\section{Acknowledgments}

The authors thank all study participants.

\section{Conflict of Interest}

The authors declare that they have no conflict of interest. 


\section{References}

[1] Heydari I, Radi V, Razmjou S et al. Chronic complications of diabetes mellitus in newly diagnosed patients. Intl J Diabetes Mellitus 2010; 2: 61-63

[2] Piechota G, Malkiewicz J, Karwat ID. Type 2 diabetes mellitus as a cause of disability. Przegl Epidemiol 2004; 58: 677-682

[3] Tabesh M, Shaw JE, Zimmet PZ et al. Association between type 2 diabetus mellitus and disability: What is the contribution of diabetes risk factors and diabetes complications? J Diabetes 2018; 10: 744-752

[4] Holman R. Metformin as first choice in oral diabetes treatment: The UKPDS experience. J Annu Diabetol Hotel Dieu 2007; 13-20

[5] Riedel AA, Heien $\mathrm{H}$, Wogen J et al. Loss of glycemic control in patients with type 2 diabetes mellitus who were receiving initial metformin, sulfonylurea, or thiazolidine monotherapy. Pharmacotherapy 2007; 27 : $1102-1110$

[6] Handelsman Y, Bloomgarden ZT, Grunberger G et al. American Association of Clinical Endocrinologists and American College of Endocrinology-clinical practice guidelines for developing a diabetes mellitus comprehensive care plan-2015. Endocrine Practice 2015; 2: 1-87

[7] Turner RC, Cull CA, Frighi V et al. Glycemic control with diet, sulfonylurea, metformin, or insulin in patients with type 2 diabetes mellitus: Progressive requirement for multiple therapies (UKPDS 49). UK Prospective Diabetes Study (UKPDS) Group. JAMA 1999; 281: 2005-2012

[8] Bell DS. Combine and Conquer: Advantages and disadvantages of fixed-dose combination therapy. Diabetes Obesity. Metabolism 2013; 15: $291-300$

[9] Tripathi KD. Insulin, Oral Hypoglycemic Drugs and Glucagon. In: Essentials of Medical Pharmacology. 7th edn. JP Medical Ltd; 2007: 258-280

[10] White JR. A brief history of the development of diabetes medications. Diabetes Spectrum 2014; 27: 82-86

[11] Bodmer M, Meier C, Krähenbühl S et al. Metformin, sulfonylureas, or other antidiabetics drugs and the risk of lactic acidosis or hypoglycemia. Diabetes Care 2008; 31: 2086-2091

[12] Rao AD, Kuhadiya N, Reynolds K et al. Is the combination of sulfonylureas and metformin associated with an increased risk of cardiovascular disease or all-cause mortality?: A meta-analysis of observational studies. Diabetes Care 2008; 31: 1672-1678

[13] Roumie CL, Greevy RA, Grijalva CG et al. Association between intensification of metformin treatment with insulin vs. sulfonylureas and cardiovascular events and all-cause mortality among patients with diabetes. JAMA 2014; 311: 2288-2296

[14] Udell JA, Bhatt DL, Braunwald E et al. Investigators Saxagliptin and cardiovascular outcomes in patients with type 2 diabetes and moderate or severe renal impairment: observations from the SAVOR-TIMI 53 Trial. Diabetes Care 2015; 38: 696-705

[15] Hamdan A, Idrus RH, Mokhtar MH. Effects of Nigella sativa on type-2 diabetes mellitus: A systematic review. Int J Environ Res Public Health 2019; 16: 4911-4923

[16] Heshmati J, Namazi N. Effects of black seed (Nigella sativa) on metabolic parameters in diabetes mellitus: A systematic review. Complement. Ther. Med 2015; 23: 275-282

[17] Yimer EM, Tuem KB, Karim A et al. (Black Cumin): A promising natural remedy for wide range of illnesses. Evid. Based Complement. Altern Med 2019; 6: 1-16

[18] Ahmad A, Husain A, Mujeeb M et al. A review on therapeutic potential of Nigella sativa: A miracle herb. Asian Pacific J Tropical Biomed 2013; 3: $337-352$

[19] Jehan S, Zhong C, Li G et al. Thymoquinone selectively induces hepatocellular carcinoma cell apoptosis in synergism with clinical therapeutics and dependence of p53 status. Front. Pharmacol 2020; 11: 555283
[20] Kassab RB, El-Hennamy RE. The role of thymoquinone as a potent antioxidant in ameliorating the neurotoxic effect of sodium arsenate in female rat. Egyptian J Basic Appl Sci 2007; 4: 160-167

[21] Umar S, Zargan J, Umar K et al. Modulation of the oxidative stress and inflammatory cytokine response by thymoquinone in the collagen induces arthritis in Wistar rats. Chem Biol Interact 2012; 197: 40-46

[22] Bamosa AO, Kaatabi H, Lebdaa FM et al. Effect of Nigella sativa seeds on the glycemic control of patients with type 2 diabetes mellitus. Ind J Physio and Pharmaco 2010; 54: 344-354

[23] Mahmoud YK, Saleh SY, El Rehim A et al. Biochemical efficacy of Nigella sativa oil and metformin on induced diabetic male rats. J Animal and Vet Sciences 2014; 9: 277-284

[24] Ventura-Sobrevilla J, Boone-Villa VD, Aguilar CN et al. Effect of varying dose and administration of streptozotocin on blood sugar in male cd1 mice. Proc West Pharmacol Soc 2011; 54: 5-9

[25] Fararh KM, Shimizu Y, Shina T et al. Thymoquinone reduces hepatic glucose production in diabetic hamsters. Res Vet Sci 2005; 79: 219-223

[26] Sabzhabaee AM, Dianatkhah M, Sarrafzadegan N et al. Clinical evaluation of Nigella sativa seeds for the treatment of hyperlipidemia: A randomized, placebo controlled clinical trial. Medical Archives 2012; 66: 198-200

[27] El-Shamy KA, Mosa MM, El-Nabarawy SK et al. Effect of Nigella sativa tea in type 2 diabetic patients as regards glucose homeostasis, liver and kidney functions. J Applied Sci Res 2011; 7: 2524-2534

[28] Kaatabo H, Bamosa AO, Badar A et al. Nigella sativa improves glycemic control and ameliorates oxidative stress in patients with type 2 diabetes mellitus: placebo controlled participant blinded clinical trial. PLoS One 2015; 10: e0113486

[29] Häring HU, Merker L, Seewaldt-Becker E et al. EMPA-REG Trial Investigators. Empagliflozin as add-on to metformin plus sulfonylurea in patients with type 2 diabetes: A 24-week, randomized, doubleblind, placebo-controlled trial. Diabetes Care 2013; 36: 3396-3404

[30] Sakura H, Hashimoto N, Sasamoto K et al. Effect of sitagliptin on blood glucose control in patients with type 2 diabetes mellitus who are treatment naive or poorly responsive to existing antidiabetic drugs: The JAMP study. BMC Endocrine Disorders 2016; 16: 70-81

[31] Rosenstock ], Mathieu C, Chen $\mathrm{H}$ et al. Dapagliflozin versus saxagliptin as add-on therapy in patients with type 2 diabetes inadequately controlled with metformin. Arch Endocri and Metabol 2018; 62: 424-430

[32] Alimohammadi S, Hobbenaghi R, Javanbakht J et al. Protective and antidiabetic effects of extract from Nigella Sativa on blood glucose concentrations against streptozotocin (STZ)-induced diabetic in rats: an experimental study with histopathological evaluation. Diagn Pathol 2013; 8: 137

[33] Benhaddou-Andaloussi A, Martineau LC, Spoor D et al. Antidiabetic activity of Nigella sativa seed extract in cultured pancreatic $\beta$-cells, skeletal muscle cells, and adipocytes. Pharmaceutical Biology 2008; 46: 96-104

[34] Fararh KM, Atoji Y, Shimizu Y et al. Mechanisms of the hypoglycaemic and immunopotentiating effects of Nigella sativa L. oil in streptozotocin-induced diabetic hamsters. Res Vet Sci 2004; 77: 123-129. PMID: 15196902

[35] Benhaddou-Andaloussi A, Martineau L, Vuong T et al. The In Vivo Antidiabetic Activity of Nigella sativa is mediated through activation of the AMPK Pathway and increased muscle Glut4 Content. Evid Based Complement Alternat Med 2011; 2011: 1-9

[36] Kaatabi H, Bamosa AO, Bader A et al. Nigella sativa improves glycemic control and ameliorates oxidative stress in patients with type 2 diabetes mellitus: Placebo controlled participant blinded clinical trial. PLOS ONE 2015; 10: e0113486

[37] Nakamura M, Oda S, Sadahiro T et al. Critical Care 2012; 16: R58

[38] Wegner M, Araszkiewicz A, Piorunska-Stolzmann M et al. Association between IL-6 concentration and diabetes-related variables in DM1 patients with and without microvascular complications. Inflammation 2013; 36: 723-728 